\title{
MADRES Y PADRES EN VENEZUELA. UnA TRADICIÓN QUE SE SOSTIENE ENTRE CADENAS Y REDES MigRatorias. Caso Cartagena Y BARRANQUILLA ${ }^{1}$
}

\author{
MOTHERS AND FATHERS IN VENEZUELA. A TRADITION THAT IT MAINTAINS BETWEEN CHAINS \\ AND Migration NETWORKS. CASE Cartagena AND BARRANQUILLA
}

* MARÍA DEL PILAR MORAD HAYDAR

Profesora Titular. Facultad de Ciencias Sociales y Educación. Trabajadora Social. Magíster en Estudios de Ménero, Mujer y DesarroGénero, Mujer y DesarroIlo. Directora del Grupo de Investigación Estudios de Familia, Masculinidades y Feminidades. Universidad de Cartagena. E mail: pilarmorad@hotmail.com

** GLORIA BONILLA VÉLEZ Profesora Facultad de Ciencias Humanas. Historiadora. Magíster en Historia Ph. Estudios de Género. Ph.D Estudios de Género. Integrante Grupo de Investigación en Estudios de Familias, Masculinidades y Feminidades. Universidad de Cartagena. E-mail: gloes-

bo1810@gmail.com

***MERCEDES

RODRÍGUEZ LÓPEZ

Profesora de la Facultad de

Ciencias Sociales y Educa

ción. Trabajadora Social.

ción. Trabajadora Social.

Magister en Estudios de

Gentero, y Desarrollo. In

tegrante del Grupo de In-

vestigación en Estudios de

Familias, Masculinidades y

Feminidades. Universidad de

Cartagena.

1 Este artículo es producto de los hallazgos de la investigación inter-universitaria e gación inter-universitaria y conflictos de los grupos familiares frente a la migración internacional que se desarrolló con la coparticipación de cinco universidades colombianas: Universidad Nacional de Colombia con la profesora Colombia con la profesor zar, asumiendo la dirección general, Universidad de Antioquia, Universidad del Valle, Universidad de Caldas Universidad de Cartagena. Este proyecto fue cofinanciado por Colciencias y las universidades participantes. Aborda las áreas metropolitanas de Bogotá, Medellín, Cali, Manizales, Pereira, Cali, Manizales, Pereira Cartagena y Barranquilla. Está basado en la ponencia presentada en el IV Congreso internacional de Familias Desafíos para comprender los procesos familiares en el contexto de la migración Internacional organizado por la Universidad de Caldas.

\section{Por: Maria Del Pilar Morad Haydar" Gloria Bonilla Vélez*" Mercedes Rodríguez López***}

Artículo recibido: Agosto 11 de 2011. Artículo aprobado: Diciembre 22 de 2011

\section{RESUMEN}

Este artículo se centra en la reflexión sobre las redes familiares y las cadenas migratorias que soportan la migración de padres y madres, que se vienen sosteniendo históricamente hacia Venezuela desde algunas ciudades de la costa Caribe colombiana, como Cartagena y Barranquilla dada su proximidad fronteriza.

El análisis de los relatos de cuidadoras/es e hijas/os que se quedan en las ciudades de origen, nos permitirá comprender la dinámica del proceso migratorio hacia este país, los factores del contexto que la impulsan y el papel de las redes que reproducen el tránsito permanente de padres y madres en busca de mejores oportunidades para sus familias.

Palabras clave: Migración parental, redes familiares, cadenas migratorias, migración transfronteriza, motivos económicos, género.

\section{ABSTRACT}

This article focuses on a reflection about family networks and migratory chains of groups that support the migration of mothers and fathers that have been, historically, migrating from some Caribbean Colombian cities such as Cartagena and Barranquilla to Venezuela; a neighbor country with a borderland very close to these cities.

The analysis of the narration made by babysitters and children who stay in the cities where parents migrate from will allow us to understand the dynamic of this migratory process to Venezuela. We will also examine what aspects of their environment generate this migratory dynamic and what the role of this networks reproducing the permanent flux of these parents in search of better opportunities for their families is

Keys words: Family networks, migratory chains, transnational migration, economic aspects, gender 


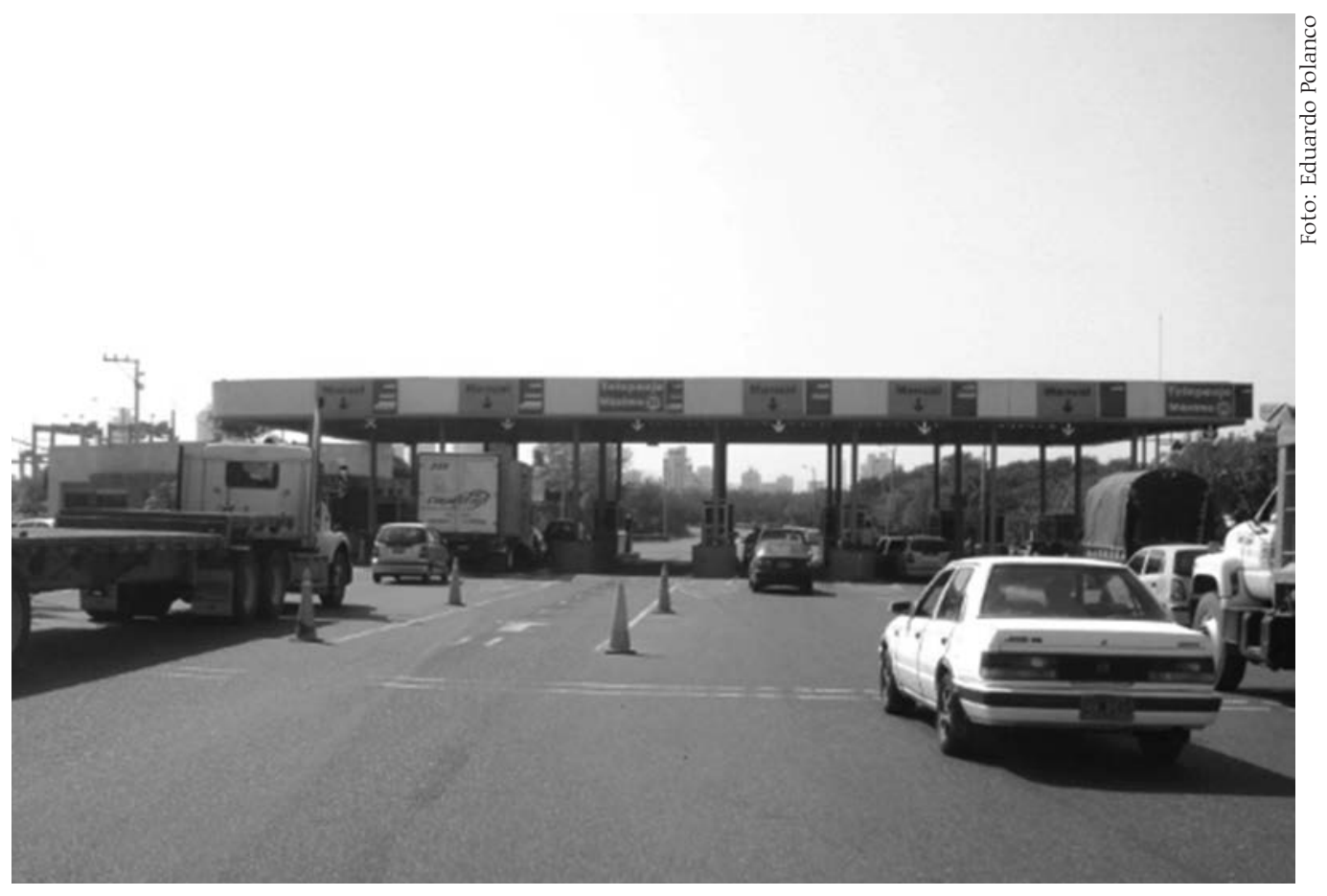

"Entrada" Cartagena 2012

\section{Introducción}

La migración internacional de colombianos/as en las últimas décadas del siglo XX y primera del XXI, ha despertado el interés de las ciencias sociales en categorías de análisis como las familias en situación de transnacionalidad y el aporte de la perspectiva de género en la comprensión de las transformaciones que vienen presentando las dinámicas familiares en el contexto de las sociedades contemporáneas.

Las condiciones económicas y sociales del país, en especial el desempleo, la precariedad del mismo, la inequidad social y la falta de ingresos suficientes para satisfacer las necesidades de las familias, se entrecruzan junto a otros factores, incidiendo en que el país se convierta en expulsor de población, obligando a que las personas migren con la expectativa de alcanzar mejores niveles de vida. Si a esto sumamos, la inseguridad, la violencia en los contexto urbanos y rurales como consecuencia del conflicto armado, la migración se va a convertir en una salida indispensable para un grupo amplio de población (Puyana, et.al. 2010:50).

La migración colombiana ha venido presentando cambios importantes en cuanto a la elección de los países de destino, la creciente migración femenina, las condiciones socio-económicas y perfiles de quienes migran, entre otras, 
impactando no solo en la economía de los países, sino además, en las relaciones transnacionales que se sostienen entre aquí y allá (Puyana, 2009), con sus consecuentes transformaciones en las dinámicas familiares, que hoy son objeto de interés académico en las distintas regiones del país.

Con la presente reflexión pretendemos aportar al análisis de la emigración de madres y padres, a partir de datos históricos y fuentes orales, recurriendo a los relatos de familiares que quedan en las ciudades de origen como Cartagena y Barranquilla, y que dan cuenta de los flujos migratorios sostenidos hacia Venezuela pese a los cambios económicos, políticos y sociales que los países vienen presentando y sus consecuentes repercusiones en sus políticas migratorias.

Son pocos los estudios identificados que además de analizar los flujos y las olas migratorias hacia Venezuela ${ }^{2}$ se interesan por comprender por qué las familias continúan sosteniendo esta tradición histórica. La necesidad de contribuir a su comprensión, a visibilizar la situación de nuestros connacionales en este país, es apremiante, además de aportar estos hallazgos para la construcción de políticas en materia de derechos y oportunidades reales para las familias que salen del país por motivos económicos y / o laborales. Intentaremos provocar el debate y nuevas preguntas alrededor de este tema.

\section{Aspectos históricos de la emigración de colombianos/as hacia Venezuela}

2 Algunos de estos estudios sobre la migración a Venezuela: Dávila 2007; Álvarez, 2004, 2006, 2007 Bidegaín 1987, Bermúdez, 1976, Gómez y Mora, 1972,

Ungar, 1995, Villafañe,

1983, Murillo, 1979, 1999,

Torralba, 1987, Gómez y

Díaz 1999.
La revisión de estudios como el de Raquel Álvarez, sobre la evolución histórica de la migración a Venezuela permite identificar que desde 1950, este país ha funcionado como receptor de mano de obra colombiana calificada, no calificada y campesina, principalmente en zonas fronterizas, por las relaciones de vecindad, permeabilidad de las fronteras y facilidades comunicacionales que actúan como factores a favor de esta migración (Álvarez, 2004:191-194).

La historia demográfica de Venezuela, tal como lo plantea Miguel Bolívar ha experimentado dos períodos significativos de inmigración. El que siguió inmediatamente después de la Segunda Guerra Mundial y el que coincidió con las grandes decisiones de política económica gubernamental que incidieron en las relaciones de propiedad o control por parte del Estado sobre los principales recursos naturales -petróleo, hierro y aluminio- generadores de divisas para el fisco. En el primer momento, hubo un predominio europeo (principalmente españoles, italianos y portugueses) y una leve cuota de países latinoamericanos (Bolívar, 1993:2). En el segundo, la migración 
latinoamericana fue la dominante. Pero en ambos periodos hubo una presencia significativa de los colombianos de las fronteras norte y oriente ${ }^{3}$.

Según los censos de población de Venezuela, el número de colombianos y colombianas residenciados entre los años 1951 y 1971 tuvo una variación importante, pasando de 45.969 a 180.314 habitantes (Gonzáles, 2000:89). Estas corrientes migratorias provenían básicamente del otro lado de la frontera, siendo los habitantes de la Región Caribe y Antioquia quienes se dirigían hacia el estado de Zulia. Mientras los residentes en los departamentos de la región andina, se trasladaron hacia el Táchira, Barinas, entre otros estados. Caracas siempre fue considerada como uno de los grandes polos de atracción para los migrantes colombianos (Álvarez, 2006:5) al igual que las principales ciudades del país: Maracaibo, Barquisimeto, Valencia, San Cristóbal (Álvarez, 2007:12; Dávila, 2002:12).

Algunos estudios realizados sobre la población migrante colombiana en la época de la explosión demográfica clandestina hacia Venezuela (1974-1982), la presentan como una migración mayoritariamente masculina, mientras las mujeres migrantes alcanzaban un 20\% de esta población indocumentada; por otra parte, migraban en edad productiva, y con bajos niveles de escolaridad, con la particularidad que viajaban solos y tenían a sus familiares en Colombia. Los motivos más frecuentes por los cuales migraban eran el desempleo y la búsqueda de mejores salarios (Dávila, 2002:9). Los colombianos presentaban relativa facilidad para ubicarse laboralmente, con el apoyo de amigos o familiares establecidos de manera regular o clandestinamente, lo cual evidencia la importancia histórica de su atractivo económico y de las redes familiares y sociales que han sostenido un mercado laboral transfronterizo. (Murillo, 1979:3 y Dávila, 2002:11)

Según el estudio de Gabriel Murillo, el caso de Venezuela llama la atención porque se trata de una "emigración de los estratos bajos populares de ciudades como Cúcuta, Cartagena, Barranquilla, Bucaramanga y Riohacha". (Murillo, 1979: 65). Gómez y Mora además encontraron que las edades tanto de hombres como de mujeres emigrantes desde Colombia, en su mayoría eran jóvenes menores de 30 años, desplazamiento que afectaba la composición familiar y la distribución espacial en el país (1972: 15).

Por su otra parte, en el periodo de 1960 a 1973 llega a Venezuela una significativa corriente migratoria de colombianos atraídos por las

${ }^{3}$ Según este mismo autor, la vecindad territorial de ambos países, la casi identidad lingüística, la homogeneidad cultural entre algunas regiones colombianas y venezolanas... y hasta la historia compartida, ha hecho que colombianos y venezolanos estén separados solo por un documento de identidad que acuña lazo legal a una pertenencia nacional artificialmente construida y fomentada. Por ello, los colombianos han sido, desde el punto de vista formal, la nacionalidad más representada dentro de la construcción de la identidad demográfica de Venezuela (Bolívar, 1992:194). 


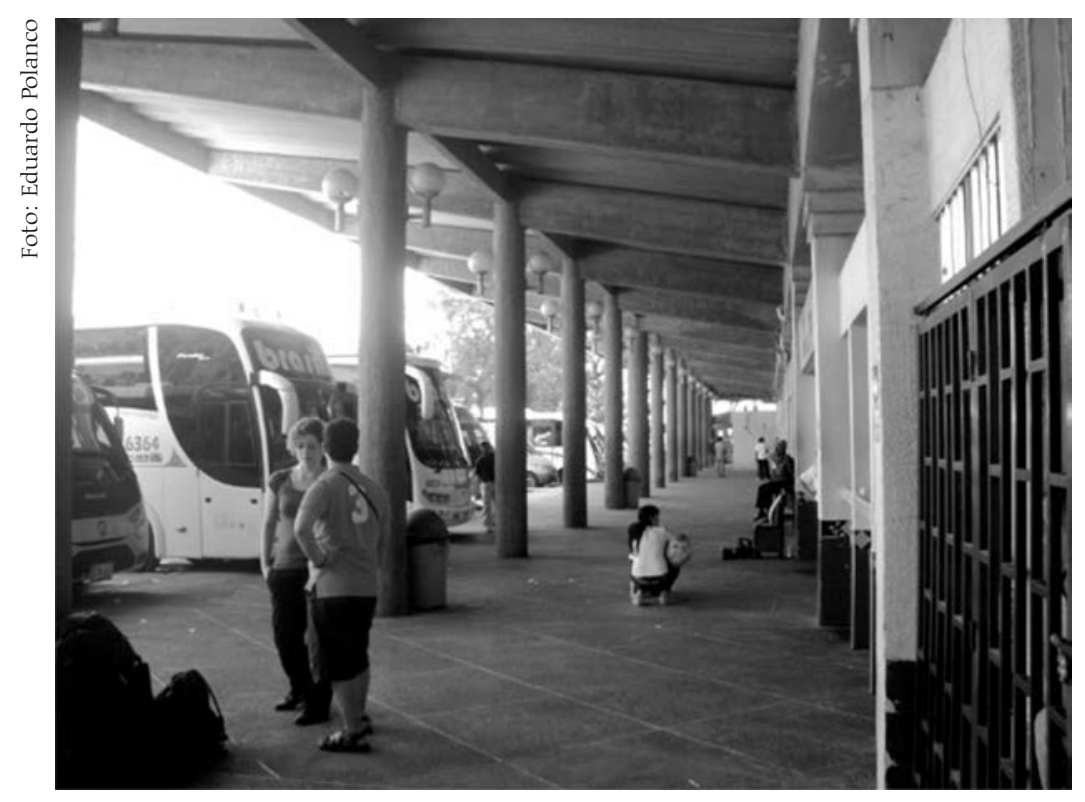

"Salida" Cartagena 2012

oportunidades generadas por el petróleo ante la imposibilidad de acceder a mayores ingresos que en su país de origen (Torralba, 1987:9; Bidegaín, 1987:20; Bidegaín y Frietz, 1989:89).

Otros estudios muestran además que el patrón distintivo de la migración dentro de la subregión andina refleja que el flujo de colombianos hacia Venezuela es el de mayor cuantía y visibilidad entre los intercambios migratorios. Los colombianos en Venezuela representaban el 76\% del total de migrantes intracomunitarios hacia 1990. Esta nación aglutina al 84\% de los inmigrantes y Colombia aporta el 82\% de los emigrantes andinos (Cepal-Celade, 2007:34).

\section{La emigración del Caribe colombiano a Venezuela}

Para el caso de emigrantes desde Colombia a Venezuela las principales áreas de expulsión migratoria, la constituyen las rurales y fronterizas debido a las precarias condiciones existentes que impiden satisfacer las necesidades mínimas de subsistencia, como resultado sus pobladores optan por migrar hacia otros departamentos o estados con mayores posibilidades de desarrollo (Puyana, et.al., 2010:77).

Los flujos migratorios de colombianos a Venezuela, señalan la presencia de población campesina tanto por la frontera norte-santandereana, como por la frontera de la costa norte colombiana por la península de la Guajira, procedentes de los departamentos de Bolívar, Sucre, Córdoba, Magdalena y Atlántico (Arana, 2000: 22; Díaz y Gómez, 1999:23; Álvarez, 2004: 8, Barglaund y Hernández, 1985:20). Según los estudios de Murillo, "uno de los departamentos con más población emigrante a Venezuela es el de Bolívar y Cartagena junto a otros municipios y corregimientos de la zona norte del país es uno de los que más ha expulsado población trabajadora" (Murillo, 1979:7). 
La emigración hacia Venezuela se produjo en forma masiva a partir de la crisis económica de la región Caribe colombiana a finales de los sesentas. En el censo de 1971 de Venezuela, se reportan 270.000 colombianos, de las cuales un $68 \%$ era de la zona norte de Colombia principalmente de los departamentos de Bolívar, Atlántico, Sucre, Córdoba y la Guajira (Murillo, 1979:3). En 1990 el censo de población de Venezuela arroja el dato de 590.000 colombianos residentes allí (Anuario Estadístico de Venezuela, 1991:34).

Una de las causas que explican el porqué de esta situación es que Bolívar tiene cultivos estacionales y se practica la pesca artesanal. Estas actividades permiten la masiva emigración de bolivarenses hacia Venezuela, estableciéndose una inserción laboral temporal y un retorno circular y transitorio. Otros grupos de migrantes logran quedarse por mayor tiempo, porque encuentran diversos trabajos no calificados (albañiles, empleadas del servicio doméstico) en los cuales se ubican de manera más permanente.

Los emigrantes bolivarenses a Venezuela tenían el anhelo de alcanzar un progreso económico en la Venezuela del "petrodólar". No obstante, ya fuera en su condición de regularidad o "irregularidad", se ubicaban en las actividades de más baja remuneración laboral. Se trataba de jóvenes, que tenían la habilidad de sortear las dificultades en la trochas, con un nivel de escolaridad muy bajo y procedían de las zonas rurales. Pasando la frontera y en territorio venezolano, se dedicaban a labores del campo porque estaban familiarizados con ese trabajo en Colombia (Murillo, 1979:25).

El flujo de migración campesina a Venezuela estaría relacionado con las políticas de orden nacional y departamental dirigidas al desarrollo de la región de Bolívar como zona agroindustrial sin beneficiar a los pequeños propietarios, ni a los campesinos sin tierra. Esto podría ayudar a comprender porque este grupo de población venía emigrando a Venezuela en busca de nuevas oportunidades. La prensa local desde los años setenta, ilustraba esta situación: "Los campesinos de Bolívar siguen queriendo viajar a Venezuela en busca de mejores oportunidades laborales. Los salarios que devengan allí son más atractivos y les resulta mejor irse que quedarse" ${ }^{4}$ (El Universal, Cartagena, abril 5 de 1970: 4).

Otra forma de migración de bolivarenses hacia el vecino país, ha estado identificada con aquellos grupos dedicados a la práctica de actividades irregulares para el ingreso de personas ${ }^{5}$, el comercio ilegal de mercancías,

4 El titulo de este artículo fue: "Campesinos emigran a Venezuela".

5 Algunos relatos de las investigaciones citadas, permiten identificar que en lugares como La Raya donde se divide geográficamente Colombia de Venezuela, se da una participación importante de la etnia Wayúu, quienes al tener el permiso para transitar libremente para los dos países, ayudan a las personas a traspasar la frontera, a cambio de una frontera, a cambio de una retribución económica. La estrategia utilizada por ellos es disfrazar a los migrantes con la vestimenta indígena y pasarlos por las trochas $\mathrm{y}$ trayectos donde no hay presencia policiva (Puyana, et.al., 2010:121; Morad, et.al., 2011:95). 
evadiendo los controles migratorios, tal como podemos observarlo en el siguiente relato:

"Con la cuestión de los documentos, él se fue por el lado de Cúcuta (se refiere a su padre) y ahí hay personas que se encargan de meter a quienes no tienen documentos, cobrándoles cierta cantidad de dinero, creo que fueron 160.000 bolívares hasta llevarlo al lugar a donde iba. A esos señores les llaman pequiperos, que son los que se encargan de meter a las personas por trochas a Venezuela". (Hijo, Barranquilla).

Por otra parte, la proximidad geográfica entre la costa norte colombiana y su conexión con las fronteras venezolanas ha facilitado históricamente el contrabando por la Guajira, un tema que fue y ha sido motivo de preocupación y tensión entre los dos países (Suárez, 2000:32) .

Los patrones de procedencia y destino de la migración de Cartagena y Barranquilla a Venezuela han cambiado. El ritmo de la emigración, aunque no necesariamente su magnitud relativa, fue de mayoría procedente del sector rural en los años sesenta y setenta (Murillo y Ardila, 1999:34), lo cual está correlacionado con el mayor crecimiento de la pobreza y el desempleo en esta región. En los años ochenta y noventa se observó una mayor emigración de población urbana procedente de estas capitales.

En cuanto a los estratos sociales se ha confirmado que la migración a Venezuela la conforman personas que provienen de los sectores socioeconómicos más pobres (DANE, 2005), esto se facilita porque no se requieren altos costos en el viaje, ni para el ingreso al país donde en muchos casos, tienen parientes que los acogen mientras que logran insertarse laboralmente. Así lo expresa una tía de Barranquilla, al relatar por que eligen a Venezuela.

${ }^{6}$ El periódico El Universal de Cartagena de 16 de mayo de 1963 destaca como en la zona fronteriza del estado de Zulia, la región petrolera más rica de Venezuela se ha venido operando la construcción

de haciendas provocanto el éxodo hacia Venezuela de obre en "búsqueda de trabajo", a su vez incrementándose el contrabando que introducían diariamente por el distrito de Maracaibo".
"Ella se fue, primero, porque las condiciones monetarias, su anhelo era irse para Estados Unidos, pero en ese entonces los medios no le alcanzaban para que ella se fuera a Estados Unidos, y decidió irse para Caracas". (Tía cuidadora, Barranquilla).

"Porque en Venezuela como en todos los tiempos hasta ahora, es el país más cerca de Colombia es el que todos ven más fácil el ingreso y es el que las personas piensan que hay como mejores trabajos y mejor agilidad para mandar dinero para que las personas sigan subsistiendo de ellos". (Hijo, Cartagena). 
"Porque en Venezuela tiene a la hermana, y Venezuela yo creo que es el país donde uno más fácil puede entrar". (Madre cuidadora, Barranquilla)

Finalmente, es preciso advertir que la migración femenina a Venezuela ha sido una constante. Los relatos dejan entrever hasta tres generaciones de mujeres emigrando a Venezuela desde la década de los setenta; primero, las que hoy son abuelas, luego viajan las hijas y ahora es perfectamente posible que sean las nietas las que traspasan la frontera en busca de un mejor trabajo. Esto tiene que ver con varios factores como la existencia de una demanda internacional de trabajadoras del ámbito doméstico, mejores salarios que los percibidos en Cartagena y Barranquilla en la misma actividad, además de la experiencia de éxito y prosperidad construida por sus antecesoras.

Por su parte, de acuerdo a los datos del último censo (DANE, 2005) ${ }^{7}$ en Cartagena, se sigue identificando un importante flujo migratorio hacia Venezuela, situación también encontrada en Barranquilla. Los relatos revelan que quienes migran a Venezuela lo hacen por factores como la situación de pobreza de las familias, que se constituye en uno de los motivos más importantes para que padres y/o madres tengan que migrar en busca de mejores oportunidades. Esta situación podría estar relacionada con el contexto económico de Cartagena y Barranquilla que en los últimos diez años ha estado afectada por el creciente desempleo, el subempleo reflejado en la informalidad, la inestabilidad laboral y los ingresos bajos e insuficientes para cubrir las necesidades básicas de los hogares. Cartagena en los últimos estudios de Planeación Nacional y de Naciones Unidas (2000 a-2010) se ubica después de Chocó, como una de las ciudades con los más altos niveles de pobreza (DNP, 2007:129).

Así lo relatan algunos familiares entrevistados:

"Él trabajaba donde le saliera, así que si de pronto lo necesitaban un día pa' de ayudante, que pa' albañilería, el se iba, pero trabajo fijo, fijo, no tenía". (Hijo, Cartagena).

"Mi mamá era la que trabajaba aquí, pero la plata no le alcanzaba, porque lo que se ganaba era el mínimo". (Hija, Cartagena).

"Mi mamá se fue por la falta de empleo, aquí no encontraba trabajo, por eso la ayudó mi tío que ya estaba en Venezuela". (Hija, Cartagena).
${ }^{7}$ El censo que realizó durante el año 2005 el Departamento Administrativo Nacional de Estadística (DANE) reveló que un porcentaje importante de cartageneros tienen algún tipo de experiencia migratoria, ya sea porque un familiar vive en el exterior o porque ellos mismos han viajado. Las diferencias encontradas están relacionadas con sus condiciones socioeconómicas de acuerdo a econatificación social de la estratificacion social ciudad. En los estratos más altos, el censo reveló que el $6,6 \%$ de las familias tiene algún familiar viviendo en el exterior, mientras en los estratos más bajos este porcentaje llega al 0,9\%. En los países de destino también se encontraron diferencias. Los estratos altos emigran hacia Estados Unidos $(61,9 \%)$, España (el 8,7\%) y Canadá $(5,7 \%)$. Mientras los estratos bajos tienen como principal destino a Venezuela $(88,3 \%)$, seguido por Panamá $(4,5 \%)$ y en por Panamá $(4,5 \%)$ y en Unidos con el 2,8\%. 
${ }^{8}$ Se ha encontrado diversidad de formas familiares en los hogares de origen de los migrantes en Cartagena y Barranquilla, como los hogares monoparentales por separación de la pareja u hogares conformados por hijos ante la migración de padre y madre, con un apoyo importante de la famili extensa en la mayoría de los casos. (Morad, Bonilla y Rodríguez, 2011:66)
"Aquí uno trabaja y trabaja, y las cosas no las ve productivas, la plata no le alcanza y uno ve personas que emigran, y a los dos o tres años logran cosas que acá a pesar de todo el tiempo que estuvieron trabajando, no las pudieron lograr; en esa parte, sí persiste que las personas emigren hacia Venezuela". (Prima cuidadora, Barranquilla).

"Mi papá tomó la decisión de irse hacia Caracas porque tenía como un año que no conseguía trabajo y nosotros somos tres hijos y es el que corre con todos los gastos de nosotros". (Hijo, Barranquilla).

\section{Las redes familiares y las cadenas migratorias hacia Venezuela}

En el contexto de la migración internacional las redes se entienden como un "conjunto de vínculos interpersonales que conectan a migrantes, antiguos migrantes y no migrantes en su área de origen y de destino a través de los lazos de parentesco, amistad y comunidad de origen compartida" (Massey y Arango, 1993). La decisión de emigrar no ocurre en términos de opciones personales realizadas de forma individual y aislada por cada emigrante. Por el contrario, tanto la toma de decisiones como el abastecimiento de los recursos necesarios se produce en el contexto del grupo familiar nuclear, ampliado o extenso ${ }^{8}$.

Las redes y las cadenas migratorias suponen analizar un proceso colectivo que involucra a varias generaciones del grupo doméstico cuyas decisiones están condicionadas por elementos materiales y simbólicos. Las primeras decisiones dan origen a las cadenas migratorias que involucran relaciones de parentesco, amistad y vecindad, lazos comunitarios previos y la preexistencia de redes sociales tanto en la sociedad de origen como de llegada, las cuales configuran estructuras mayores: las redes migratorias (Pedone, 2006:101).

Las redes contribuyen a menguar la incertidumbre que lleva consigo la decisión de migrar, en tanto el sistema de ayudas que aporta la red ofrece algunas garantías y seguridades al evento migratorio tanto en la preparación de la migración desde el país de origen hasta la llegada al país destino. La constitución de redes de parientes y vecinos se convierte en una fuente de información que otorga una cierta seguridad para impulsar la migración, esta dinámica, en algunos casos, puede llegar a ser más importante que las causas de expulsión (Pedone, 2006: 121). 
Los relatos revisados también dan cuenta del dinamismo de las redes familiares desde los años sesenta y ochenta, sosteniendo el flujo migratorio entre los dos países, ayudando a ubicarlos laboralmente y a sostenerse en Venezuela hasta que lograran la reunificación familiar.

"Tengo nueve hermanas en Venezuela. Una hermana desde joven se fue, después mandaron a buscar a la otra, y así, total que todas se fueron, las últimas y las mayores están allá, porque tengo una hermana que está pensionada allá. Porque mis hermanas venían y me veían pasando trabajo y yo no tenía donde vivir y ellas me decían mi hermanita, vamos que con lo que tú te ganes en cinco años compras tu casa, porque ya todas tienen casa y así yo lo hice, yo cerré los ojos dejé a mis hijos con mi suegra y me fui y trabajé cinco años con una familia. Y yo mandé a mi hija para allá, y lleva diez años también en casa de familia, se fue a trabajar para ayudar a levantar a sus hijos". (Abuela cuidadora, Cartagena).

Hay varios parientes que viven allá, hay una tía que es la que le sigue a mi mamá; que ya tiene cuarenta años de estar allá. Ella fue la primera que se fue; y a partir de ahí ya todos se fueron yendo, como te digo; ellas son seis con mi mamá, y prácticamente allá se han hecho cuatro, una que está aquí y es pensionada ya; y otra que sale pensionada este año en Venezuela". (Hija Barranquilla).

"Mi abuela fue la primera que se fue a Venezuela, ella vivió cuarenta años se regresó hace ocho años, poco a poco se fue llevando los hijos, y hoy en día viven allá siete hijos de los diez que tiene; en Caracas y Maracaibo viven varios hermanos de mi abuela que son ya de allá prácticamente". (Hija, Cartagena).

Los relatos anteriores permiten identificar no solo las redes familiares que sostienen la migración entre los dos países, sino la cadenas migratorias y de cuidado que se reproducen intergeneracionalmente, teniendo en cuenta que el trabajo doméstico y de cuidado, es una de las mayores ofertas laborales para las madres migrantes ${ }^{10}$ como actividades adscritas culturalmente a las mujeres, observando que se siguen reproduciendo en los países de destino. La migración en este caso, se viene constituyendo en una oportunidad para acceder a una vivienda, a una pensión, brindar educación a sus hijos e hijas, proyectos que no veían posible realizar en Cartagena o Barranquilla, convirtiéndose en un factor atractivo para otras migrantes potenciales.
9 La numerosa comunidad colombiana establecida legalmente $(227.000$ personas para mediados de 1979) operaba, al mismo tiempo, como un factor de atracción de inmigrantes al país bajo la modalidad de "reunificación familiar". Adicionalmente, se hizo evidente un flujo turístico de familiares, parientes y amigos de migrantes ya legalizados, sobre todo colombianos, dadas las facilidades de acceso por la condición de países vecinos, de los cuales un alto porcentaje entraban con la finalidad de residir entre el resto de la población colombiana con residencia y empleo irregular en Venezuela (Davila,2002:7). El estudio de Freire, también muestra como las migraciones que han conectado algunas comunidades rurales en Colombia y Venezuela han contribuido a la formación de una de las zonas de una de las zonas de América Latina. Estas relaciones están basadas en lazos de amistad, familiares y múltiples vínculos económicos unidos a la herencia histórica y cultural común. Durante las últimas décadas a partir de los años 60 s las regiones de ambos lados de la frontera de Venezuela y Colombia han experimentado un fuerte proceso de integración tanto económico como social. económico como social. E desarrollo de una economía basada en el cultivo de hortalizas en los valles altos venezolanos promovidos por las políticas de desarrollo de los gobiernos desde Caracas en los años setenta, fue uno de los motores fundamentales de ese nuevo periodo de relaciones entre ambas regiones. Como consecuencia de esto valles altos venezolanos pasaron de ser una región deprimida a ser una de las regiones agrícolas de mayor crecimiento. (Freire, 2004: 305-325.)

${ }^{10}$ Nuestra investigación ha identificado un importante grupo de mujeres cabezas de familia, conformando hogares monoparentales ante la separación, muerte o abandono de sus parejas. Las actividades en las que se ubican con mayor facilidad está el cuidado de niños y ancianos, empleadas domésticas, ayudantes en domésticas, ayudantes en
restaurantes. Mientras los restaurantes. Mientras los
hombres se ubican en la construcción, el comercio. 
La emigración colombiana contemporánea está relacionada con motivos económicos familiares comprometiendo a más de un miembro de la familia, y, por otro lado, si bien existen decisiones individuales, la aprobación y soporte de la familia es muy importante, en términos económicos y afectivos.

En relación a este punto, cabe destacar, como lo demuestra el estudio de Herrera y Martínez, en el sentido de que no todos los miembros de la familia actúan en igualdad de condiciones y poseen la misma capacidad de acción, existen relaciones de poder, valores culturales e ideológicos que marcan los roles, las identidades de género y las condiciones de reproducción de los individuos (2004:39). Esto sumado a la activación de las redes familiares y sociales, estaría influyendo en la decisión de migrar, en el destino de la migración y en quien migra. La emigración es también una estrategia familiar de movilidad y de cambio, lo que se busca son nuevas oportunidades y un mejor futuro sustentado en los imaginarios de éxito alcanzados que se constituye en un referente para la toma de la decisión por parte de nuevas generaciones de migrantes.

El sentido del proyecto migratorio está matizado por los potenciales efectos y beneficios de la familia. Estas despliegan estrategias tendientes a "gestionar" el complejo proceso de migración activando y movilizando una serie de recursos materiales y simbólicos (inversiones afectivas, organizativas). La toma de decisión y puesta en marcha del proceso migratorio, requiere de una "suerte de pacto previo" entre los miembros de la familia. Tal pacto está mediado por relaciones de poder, conflictos, negociaciones y dominación al interior de la familia -trama que se diferencia y especifica en cada caso, según determinadas relaciones de género- dinámicas que dependen de la situación del emigrante, si es padre/madre, hombre/mujer, hijo/hija.

Una vez que se toma la decisión, se desarrollan un conjunto de estrategias colectivas para la obtención de los recursos requeridos para el viaje y simultáneamente para explorar las oportunidades laborales, relaciones y posibilidades de inserción en el país de llegada. Los siguientes testimonios ejemplifican como se establecen esos pactos previos y comienzan a movilizarse:

"Bueno mi mamá se fue para Venezuela, por Maicao, hace 21 años, pues para esa época era muy fácil entrar y como mi abuela estaba en el pueblo, las dos hermanas de ella estaban allá, la llamaron que se fuera, para que trabajara y ganara más plata. Ella entró sin papeles sin nada, pagaba veinte mil pesos o menos y entraban, en esa época no 
ponían tanto pereque para entrar, entonces ya allá conoció a mí papá, que era del mismo pueblo (Guamal, Magdalena) y allá se quedaron. (Hija, Cartagena).

"Ella consultó con nosotros, entonces teníamos un televisor, ella dijo que se lo prestáramos que cuando ella estuviera allá, ella mandaba la plata del televisor o mandaba otro televisor y lo empeñamos, con esa plata fue que se fue" (Abuela, Barranquilla).

Los ejemplos anteriores nos muestran una cara de esas "unidades migratorias" (Goicoechea, 2002: 6). Las estrategias y los consiguientes cursos de acción destinados a efectivizar la migración se institucionalizan dentro del marco de propuestas que la familia establece. Los siguientes relatos muestran la migración de padres y madres hasta de cuatro décadas, que vienen alimentando la existencia de estas redes y reproduciendo el imaginario histórico sobre Venezuela a pesar de las fluctuaciones de la moneda (bolívar) y las crisis económicas de este país, continúa siendo un lugar que les ofrece mayores oportunidades y bienestar económico para ellos y sus familias.

Mi papá viajó aproximadamente en el año de 1999 y se radicó en Maracaibo, el motivo por el cual sale es por la difícil situación de trabajo. El viaja con la ayuda de mi tío paterno, quien migró hace como treinta o cuarenta años, fueron de los primeros familiares que se fueron y le decía bueno, esto acá bajó el bolívar pero al menos hay estabilidad laboral, no te están quitando del puesto de trabajo, los policías no te están persiguiendo, aquí todo lo que tu vendas, cualquier producto se comercializa rápido, el ingreso no es mucho, no vale lo mismo que el peso, pero al menos tienes con que vivir. Después se fue mi mamá, ella también tiene unos familiares allá que se fueron hace mucho tiempo. (Hija, Cartagena)

"Para que mi papá se fuera a Caracas, contó con el apoyo de un tío que vive allí hace veinte años. No solo le prestó el dinero para el viaje, sino que también le ofreció su casa por espacio de cuatro meses hasta que mi papá se instaló, consiguió trabajo, así la vida se le hizo menos dura". (Hijo, Cartagena).

"A mi mamá le ayudó una prima que se había ido para Venezuela hacía muchos años y ya era nacional de allí, la animó, le mandó el 
dinero y además le consiguió trabajo, todo para que ella se fuera, pues aquí mi mamá estaba muy mal. Mi madre lleva diez años viviendo en Venezuela, y no piensa regresarse". (Hijo, Barranquilla).

Las redes familiares constituyen un soporte prioritario en el país de origen, su apoyo es definitivo en la decisión de migrar, por cuanto el cuidado de los hijos/as que se quedan, es un asunto vital para que se viabilice el proyecto migratorio. En Cartagena y Barranquilla, la participación de la familia extensa a través de las figuras femeninas de las abuelas y las tías en el cuidado de los hijos e hijas ha sido una práctica tradicional y legitimada en todos los estratos sociales. (Morad y Bonilla, 2003:89). Algunos de estos testimonios lo confirman:

"Siempre tuvimos el apoyo de la familia, ahí estuvieron los tíos y la abuela, cuando mi mamá se va a Venezuela, nosotras, mi hermana y yo, nos quedamos viviendo con ellos". (Hija, Cartagena)

"Esto de cuidar los nietos no es fácil. Pero de todas maneras fue la forma de colaborarle a mi hija para que se fuera, la separación de la familia duele mucho. La tristeza y la ausencia de ella ha sido dura, pero todo por que pudiera tener un mejor trabajo". (Abuela, Cartagena)

Podría plantearse que tradicionalmente las mujeres han estado y están garantizando el cuidado de hijos/as para que muchas madres puedan migrar en busca de oportunidades laborales y mayores ingresos para el sostenimiento de sus hogares. De igual manera cuando migran los padres, es la madre quien queda en el país, brindado protección y cuidado a sus hijos, observando que se reproduce la inequidad de género, por cuanto son muy pocos los casos encontrados donde los padres asumen el cuidado y la protección de su prole cuando ellas migran, delegando esta función en las abuelas, tías o hermanas. Para el caso de Barraquilla, la figura femenina de las primas también aparece con una participación importante dentro de la red familiar.

"La niña estaba muy chiquita y mi prima no quería dejarla con otras personas, nos dijo que mejor la dejaba aquí que todo era de confianza. Ajá y como yo no estaba haciendo nada, yo me quedaba cuidándola... desde ese momento se quedó con nosotras y ya tiene 17 años". (Prima cuidadora, Barranquilla.) 
"Mis dos tíos se fueron para Venezuela hace más de cuarenta años, al morir mi tía en Venezuela, mi tío manda sus dos hijos, y desde ese momento, ellos viven conmigo, porque él decía que él solo, aja no podía con esos dos pela'os" (Prima cuidadora, Barranquilla).

Los relatos también dan cuenta de los cambios en la situación económica de Venezuela, asociadas a las olas migratorias y a la situación de irregularidad en la cual se encuentran gran parte de padres y madres migrantes, viendo derrumbado el sueño del país próspero, al igual que sus posibilidades de encontrar trabajo y mejores ingresos, a lo cual se suma la devaluación del bolívar con consecuencias cada vez más difíciles para las familias migrantes.

Los relatos reflejan las condiciones laborales y precarias en las que se encuentran algunos migrantes en Venezuela: bajos salarios, algunos casos sin seguridad social, desempleados y sin posibilidades de enviar remesas a sus familiares.

“Mi hija se fue pa' Venezuela, me dijo que ella le iba a mandar a sus hijos, pero plata no ha podido mandar porque la plata de allá es diferente a la de acá y esa plata no vale nada, entonces ella le manda que la ropa, mercadito, cosas así , ella les manda pa su alimentación... así cosas, porque plata no pueden, porque como ellos no tiene papeles de allá, ellos allá están trabajando sin papeles" (Abuela, Barranquilla).

"Hay veces empiezan las peleas, porque ellos no le mandan la plata completa para sus estudios, y ella dice que eso no debe ser así porque ellos saben que siempre que se va a pagar tiene que tener la plata... cuando ella no tiene para los pasajes mis hermanos o mi mamá se los dan". (Tía, Barranquilla).

${ }^{11}$ Noticia publicada por la agencia AP. junio, 2009. "Venezuela baja a la mitad remesas para familiares en el exterior" La decisión hace parte del proceso de endurecimiento del control cambiario." La Comisión de Administración de Divisas (Cadivi) redujo de 1800 a 900 dólares las de 1800 a goo dólares las autorizaciones mensuales de divisas que podrán destinarse para las operaciones de remesas a familiares que residen en el exterior. Esta medida se dio a raíz de la caída de los precios del petróleo, principalfuente de ingresos del país". 
"Ellos a pesar de que están allá, se sienten intranquilos en la parte económica de ver que no alcanzan a cubrir todo... mi hermana y yo que estamos trabajando aportamos, por ejemplo ellos no han mandado giros estos dos meses, no han podido mandar y porque hay una serie de papeleo para poder mandar, entonces nos atrasamos en los pagos". (Hija, Cartagena).

Hay muchas dificultades en el trámite de papeles como están ahora; la tramitología que hay que hacer; hay que hacer una carta apostillada y una cantidad de cosas que les están pidiendo para poder enviar dinero. Actualmente en Colombia hay una cantidad de gente que no lo está recibiendo por la cantidad de requisitos que les piden. (Hijo, Barranquilla).

El anterior análisis nos provoca diversos interrogantes: ¿La migración a Venezuela continúa siendo atractiva para padres y madres de nuestra región? O ies el contexto económico, político y social de nuestras ciudades caribeñas las que siguen provocando una migración no voluntaria ante las pocas oportunidades que aquí encuentran sus nativos en los sectores de más bajos ingresos para resolver sus necesidades básicas o ejercer sus derechos?

\section{CONSIDERACIONES FINALES}

Podríamos concluir que la continuidad en la tradición migratoria de familias de Cartagena y Barranquilla hacia Venezuela ha estado soportada históricamente en las redes familiares y sociales, las cuales han brindado apoyo inter generacionalmente durante todo el proceso migratorio, que se continúan potencializando entre los dos países, dada la proximidad cultural y territorial, los costos de transporte, el acceso y tráfico irregular transfronterizo.

El soporte y dinamismo de las redes familiares es un factor que reproduce el imaginario de prosperidad y oportunidades de los migrantes en Venezuela que se expresa en diversas acciones que trascienden las fronteras entre los dos países, tales como la ayuda económica en caso de que el padre o la madre no obtenga empleo rápidamente, vivienda, la gestión de los papeles y permisos, y el cuidado de los hijos o hijas que quedan en las ciudades o que han nacido o se han reunificado en el otro país.

Los relatos de familiares de migrantes de Cartagena y Barranquilla hacia Venezuela, nos dejan el interrogante frente a los casos donde la migración 
está orientada a la supervivencia de familias de bajas condiciones económicas, que no logran satisfacer sus necesidades básicas en nuestro país, considerando que allá podrán encontrar trabajo y mejores ingresos, que aquí no les han sido posibles. Podríamos dejar planteado que en estos casos, la migración no necesariamente ha contribuido, ni está contribuyendo a la superación de su situación de pobreza tanto en el país de origen como de destino.

La migración de padres y/o madres hacia Venezuela está soportada además, por la participación activa de las mujeres que desde la solidaridad, y relaciones de confianza, asumen el cuidado de los hijos/as que se quedan, brindando protección y apoyo, como una forma de contrarrestar el vivir entre dos países, y ejercer una paternidad y/o maternidad a través de la distancia, en medio de conflictos y tensiones.

La convergencia de estrategias colectivas e individuales y la constitución de redes familiares consolidan, dan forma y explican el circuito migratorio, pero además producen efectos de aislar y/o modular los elementos estructurales vinculados con la crisis histórica y actual de Colombia y de las ciudades de la región Caribe que las constituyen como expulsoras de población económicamente activa.

Esta migración, tanto en su composición como en su intensidad, refleja la incapacidad del estado y de la sociedad colombiana para contribuir de manera más decidida a una política migratoria que sea garante de los derechos de esta población, cuya salida se concreta para encontrar desde iniciativas individuales respuestas presionadas por sus condiciones de desempleo, precarios salarios, informalidad laboral e inseguridad entre otras.

\section{FUENTES CONSULTADAS}

\section{PERIÓDICOS}

El Universal. Cartagena de Indias, 16 de mayo de 1963.

El Universal, "Campesinos emigran a Venezuela". Cartagena, abril 5 de 1970.

\section{BIBLIOGRAFÍA}

ANUARIO ESTADÍSTICO DE VENEZUELA. Censo de 1961. Ministerio del Interior, Caracas.

ÁLVAREZ Raquel. (2007). Evolución histórica de emigrantes a Venezuela. Ministerio de Relaciones Exteriores de Venezuela, Caracas,

Palobra No. 12. Agosto de 2010 - Julio de 2011 
ÁLVAREZ, Raquel. (2004). La dinámica migratoria colombo-venezolana: Evolución y perspectiva actual. En Geoenseñanza, Vol. 9, No 2. Universidad de los Andes, Caracas, Págs. 191,194.

ÁLVAREZ, Raquel. (2006). Evolución histórica de las migraciones a Venezuela. Breve recuento. En Aldea mundo. Universidad de los Andes, San Cristóbal Venezuela.

ARANA, Luís. (2000) Transformación de la migración a Venezuela. Datos y estadísticas. Universidad Central de Venezuela. Universidad de Mérida.

BERMÚDEZ, Susy. (1976) Migración del campesino a Venezuela: Un estudio socioeconómico en dos comunidades de la Costa Atlántica. Bogotá, Universidad de los Andes.

BERGLUND S. y HERNÁNDEZ C., H. (1977). Estudio analítico de la política inmigratoria en Venezuela. Caracas: Consejo Nacional de Recursos Humanos (C.N.R.H.) y Ministerio de Relaciones Interiores.

BERGLUIND S. y HERNÁNDEZ C., H. (1985). Los de afuera. Un estudio analítico del proceso inmigratorio en Venezuela, 1936-1985. Caracas: CEPAM

BIDEGAÍN, Ana María y FRIETZ, Antonio. (1989). Colombianos a Venezuela: mito y realidad. Caracas, Centro de Estudios de la Pastoral Social y Asistencia Migratoria.

BIDEGAÍN, Ana María. (1987). Las migraciones laborales de colombianos a Venezuela. Caracas, Instituto Latinoamericano de Investigaciones Sociales.

BOLfVAR, CHOLLET, Miguel. (1993). "Migraciones externas en Venezuela: Fuentes de datos, medición e incidencia en el diseño y formulación de políticas migratorias". Seminario internacional sobre la medición de las migraciones internacionales en América Latina. OIM, Bogotá.

DÁVILA, Luis Ricardo. (2002). Fronteras confusas. Impactos sociales de la migración. En Revista Virtual de Estudios Literarios y Culturales Centroamericanos, Istmo. Universidad de los Andes, Venezuela. Disponible en: collaborations. denison.edu/istmo/.../fronteras.html. Consultada en diciembre, 2010.

DEPARTAMENTO ADMINISTRATIVO NACIONAL DE ESTADÍSTICA. DANE (2008). Estudios postcensales No. 6. Estimación de la migración 1973-2005. Centro Andino de Altos Estudios, Candane, ISBN 9789586240802. Bogotá. Colombia.

DEPARTAMENTO NACIONAL DE PLANEACION. DNP. (2007). Pobreza y desigualdad en Colombia. Bogotá.

DOCUMENTO CEPAL-CELADE-OIM. Proyecto SIMICA. (2007). Santiago de Chile.

ELIZAGA, Juan. (1980). Tasas demográficas de la migración colombiana a Venezuela. Centro Latinoamericano de Demografía. Caracas.

Encuesta Nacional 2008-2009. Resultados generales de migraciones internacionales y remesas. Observatorio Distrital de Migraciones. Bogotá D.C. Observatorio Colombiano de Migraciones. Fundación Esperanza-Red Alma Mater.

FREIRE, Germán. (2004). Migraciones rurales andinas. Un estudio a ambos lados de la frontera colombo-venezolana. En: Boletín de Antropología. V 22, No 062, págs. 305-325. 
GOICOECHEA, Alba. (2002). Familia, imaginarios y redes sociales de la migración latinoamericana. Tesis de grado. Maestría en Sociología, FLACSO, Quito.

GONZALES, Santiago. (2000). Análisis demográfico de la población colombiana en Venezuela. Universidad Central de Venezuela. Caracas. Citado en GOMEZ, Alcides. Pobreza Desarrollo, En: Realidad y perspectivas del sector agrario colombiano. Cega, Bogotá.

GÓMEZ, Alcides y MORA, Julio. (1972). Flujos migratorios de las zonas de frontera colombiana a Venezuela. Universidad de Maracaibo. Universidad Central de Venezuela. Centro de Investigaciones Demográficas. Caracas.

GÓMEZ, Alcides y DIAZ, Marina. (1999). Dinámica de las migraciones colombianas a Venezuela. Bogotá, Universidad Nacional IEPRI, Tercer Mundo Editores.

HERRERA, Gioconda y MARTINEZ, Alejandra. (2004). Género y migración en la región sur. FLACSO, Quito.

MASSEY, Douglas, ARANGO, et.al. (1993).Teorías sobre migración internacional. Una reseña y aproximación. En: Population and Development Review, 19, No. 3. Septiembre. Traducido del inglés por Augusto Aguilar Calahorro. Publicado en: Redce, No. 10-Diciembre, 2008.

MORAD, Pilar y BONILLA, Gloria. (2003). Paternidad y maternidad en Cartagena de Indias. Antes y ahora. En Puyana, Yolanda (comp.). Padres y madres en cinco ciudades colombianas. Almudena Editores.

MORAD, Pilar; BONILLA, Gloria y RODRÍGUEZ, Mercedes. (2011). "Vida familiar, vínculos parentales y migración trasnacional colombiana: cambios y permanencias". Confluenze. Revista di studi iberoamericani. Universita di Bologna, No. 11, págs. 62-78.

MORAD, Pilar; BONILLA, Gloria; RODRÍGUEZ, Mercedes; OQUENDO, Anatali y PERNETH, Leidy. (2011). Cambios y conflictos de los grupos familiares frente a la migración internacional. Caso Cartagena de Indias. Informe de Investigación inédito. Vicerrectoría de Investigaciones. Universidad de Cartagena.

MURILLO, Gabriel. (1979). La migración de trabajadores colombianos a Venezuela. Relación ingresoconsumo como uno de los factores de expulsión. Proyecto PNUD. Ministerio de Trabajo, Bogotá.

MURILLO, Gabriel. (1972) La emigración laboral de colombianos a Venezuela. Aspectos económicos y sociales. Revista CIME, Caracas.

MURILLO, Gabriel, ARDILA, Marta. (1999). Migración laboral de Colombia. Proyección de la población rural y urbana. Bogotá. Editorial Oveja Negra.

PEDONE, Claudia. (2006) Estrategias migratorias y poder. Tú siempre jalas a los tuyos. Ediciones Abya-Yala, Ecuador.

PRASCA, Sandra. (2010) Migración campesina del norte de Bolívar a Venezuela. Monografía de Grado. Departamento de Historia. Universidad de Cartagena.

PUYANA, Y; MOTOA, J Y VIVIEL, A. (2009). Entre aquí y allá. Las familias colombianas transnacionales. Bogotá: Fundación Esperanza. CÓDICE 
PUYANA, Yolanda; MICOLTA, Amparo; ESCOBAR, Maria Cénide; SÁNCHEZ, Gloria; PALACIO, María Cristina; LÓPEZ, Luz María; JIMÉNEZ, Blanca; MALDONADO, María Cristina; CANO, Nora; MORAD, Pilar; RODRÍGUEZ, Mercedes; BONILA, Gloria. (2010). Cambios y conflictos en los grupos familiares frente a la migración internacional. Informe final Colciencias. Colombia. Disponible en: www.humanas.unal.edu.co/migraciónyfamilias/.

RUBIO SALAS, Rodolfo. (2010). Redes sociales y mecanismos de apoyo a la migración. I Congreso de Estudios Demográficos, Universidad de Barcelona.

SUÁREZ, Emilio. (2000). El contrabando en la Guajira. A través de Venezuela Caracas.

TORRALBA, Ricardo. (1987). Las migraciones de colombianos a Venezuela. Universidad de los Andes, Caracas.

UNGAR, Elizabeth. (1995). Migración de colombianos a Venezuela Análisis demográfico. Centro Latinoamericano de Demografía, Santiago de Chile.

VILLAFAÑE, Pablo. (1983). Migración de colombianos al Táchira 1903-1983. Biblioteca de autores tachirenses. San Cristóbal. 


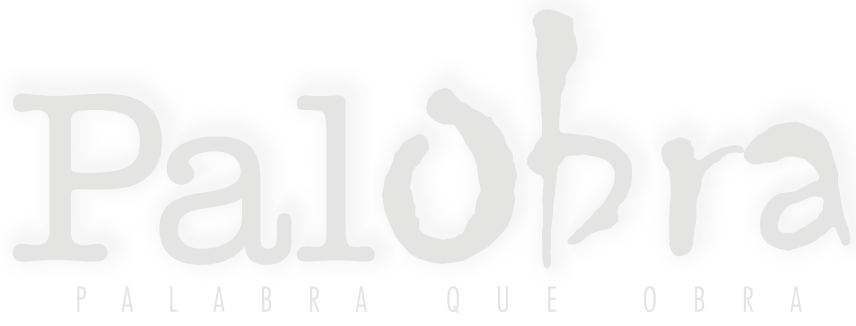

